\title{
Intelligent monitoring system of unburned carbon of fly ash for coal fired power plant boiler
}

\author{
Pogganeswaran Gurusingam ${ }^{1}$, Firas Basim Ismail ${ }^{1 *}$, Prem Gunnasegaran $^{1}$, and \\ Taneshwaren Sundaram ${ }^{1}$ \\ ${ }^{1}$ Power Generation Unit, Institute of Power Engineering (IPE), Universiti Tenaga Nasional, 43000 \\ Kajang, Selangor, Malaysia.
}

\begin{abstract}
Coal fired power plant becoming preferable power plant type to support electricity demand mainly in Asia due to stable coal price and low maintenance. However, most coal fired plant operator struggle with condition where coal undergo incomplete combustion and produced unburned carbon where can be found in ashes especially in fly ash. Higher percentage of unburned carbon in fly ash reflects the lower efficiency of furnace and contributes to financial loses for plant operators. This problem also leads to technical issues such as slagging and clinkering and further reduces the efficiency of furnace. The plant operator determines the amount of unburned carbon by using conventional method and this proves be a challenge to identify and rectify the problem on day basis due time constraint to obtain results of unburned carbon. Thus in this paper, best Artificial Neural Network model was derived to develop intelligent monitoring system to predict unburned carbon level on more daily basis. By this model, the power producer can predict the unburned carbon level by using data in power plant to predict the unburned carbon level in short period of time.
\end{abstract}

\section{Introduction}

Malaysia's largest thermal power plant uses coal as fuel source to fuel their furnace. This type of power plant was considered due to the cheap coal prices and abundant of coal reserve in the world compare to other type of thermal power plant such as natural gas and oil based power plant. As by product of the coal combustion, two type of ashes were produced and known as bottom ash and fly ash. Bottom ash usually dropped to hopper of the boiler and fly ash will be collected by electrostatic precipitator or also known as ESP and will be collected in ash silo. The ash usually contains some percentage of unburned carbon that was produced due to incomplete combustion in the boiler. The higher concentration of unburned carbon usually found in fly ash compared to bottom ash. The higher percentage of unburned carbon proved not to be good in term of financial and technical factor for the power plant operators. Fly ash also poses some problem such as air pollution, groundwater contamination and also poses some health issue especially related to respiratory system. As energy demand increase

* Corresponding author: Firas@uniten.edu.my 
and the world opted for greener environment, plant operator need to maintain higher environment friendly plant and a higher efficiency power plant. Lower carbon fly ash considered as high quality additives for cement manufacturing. High quality fly ash improve concrete strength and reduce heat of hydration of concrete [1]. Unburned carbon in the fly cannot be eliminating fully but can be reduced to significant amount. Best level of unburned carbon estimated to be around 2-5\% [2] from total fly ash. There is few method was tried such as usage on infrared light sensor to measure carbon intensity in fly ash [3], Computational Fluid Dynamic (CFD) analysis [4] and combination of ANN with other method to predict the presence of unburned carbon in fly ash $[5,6,7,8]$. Thus an intelligent monitoring system was designed to detect and predict the unburned carbon in short period of time. This system is based on Artificial Neural Network (ANN) theory. This approach was selected because it proves to produce prediction using real time data at faster and accurate compare to other existing prediction system.

\section{Result and discussion}

\subsection{CFD simulation}

Four set of simulation was carried out to find out the amount at different factor and the relation that lead to production higher unburned carbon. This simulation was done to show that the parameter that was selected for the input data influence the production of unburned carbon level. The simulation was carried out by using different rate that can lead to unburned carbon level. The simulation was done to four parameters as :

\subsubsection{Load (MW) simulation}

Two simulations were carried out to find the amount of unburned produced at two different load. The simulation was carried out for full load and half load. The simulation was done predict and study the behavior of the rate of unburned carbon produced. The simulation was done on full load and half load. The result of unburned carbon production was tabled in Table 1 below.

Table 1. Estimated unburned carbon in flue gas at different load.

\begin{tabular}{|c|c|}
\hline Load (MW) & Unburned Carbon (ppm) \\
\hline Full Load & 0.064 \\
\hline Half Load & 0.282 \\
\hline
\end{tabular}

The unburned carbon amount was recorded in parts per million (ppm) during the simulation. Simulation for full load boiler operation shows that it produce $0.064 \mathrm{ppm}$ and half load operation simulation shows the unburned carbon at 0.282 . The data show that lower load produce more unburned carbon compare to full load. Thus, it was determine that load does affect the production of unburned carbon. The lower load does produce higher rate of unburned carbon compared to full load. This due to less heat produced in the boiler and less heat can't completely burn all the carbon because carbon needs high temperature for combustion. Thus the load does affect the unburned carbon in fly ash during boiler operation. 


\subsubsection{Tilt angle of Burner $\left({ }^{\circ}\right)$}

The second test was done to find the amount of unburned carbon produced at different tilt angle. Five different angle of tilt angle was determine with $0^{\circ}$ was set as base angle with $20^{\circ}$, $10^{\circ},-10^{\circ}$ and $-20^{\circ}$. The result of simulation was presented in Table 2 below.

Table 2. Estimated unburned carbon in flue gas at different tilt angle of burner

\begin{tabular}{|c|c|}
\hline Tilt Angle $\left({ }^{\circ}\right)$ & Unburned Carbon (ppm) \\
\hline 20 & 0.065 \\
\hline 10 & 0.080 \\
\hline 0 & 0.064 \\
\hline-10 & 0.041 \\
\hline-20 & 0.110 \\
\hline
\end{tabular}

From Table 2 the result that was produced for $20^{\circ}, 10^{\circ},-10^{\circ}, 0^{\circ}$ and $-20^{\circ}$ are $0.065,0.080$, $0.064,0.041,0.11$ respective. This simulation shows result of different angle of tilt angle that influence the production of unburned carbon. The higher amount unburned carbon can be seen at $-20^{\circ}$, the lower position of burner in the boiler. The lower tilt angle usually will influence the higher amount of unburned carbon because the coal from lower position need higher time to be getting burned completely [9]. Thus it can be seen that the position of burner does influence the production of unburned carbon although it does not show a clear pattern or relationship between tilt angle of burner and unburned carbon.

\subsubsection{Coal Feeder Rate $(t / h)$}

The third simulation was carried out by manipulating the coal feed rate per hour. This simulation was carried out because this parameter varies a lot during plant operation to meet demand power plant load. Thus three simulations were carried out by using $32.32 \mathrm{t} / \mathrm{h}, 30 \mathrm{t} / \mathrm{h}$ and $26 \mathrm{t} / \mathrm{h}$ and the result was tabulated in Table 3below.

Table 3. Estimated unburned carbon in flue gas at different coal feed rate

\begin{tabular}{|c|c|}
\hline Coal Feeder Rate $\mathbf{( T / H )}$ & Unburned Carbon (ppm) \\
\hline 32.32 & 0.064 \\
\hline 30 & 0.080 \\
\hline 26 & 0.124 \\
\hline
\end{tabular}

The result that was obtained after the CFD simulation are $0.064 \mathrm{ppm}, 0.080 \mathrm{ppm}$ and 0.124 $\mathrm{ppm}$ respectively to $32.32 \mathrm{t} / \mathrm{h}, 30 \mathrm{t} / \mathrm{h}$ and $26 \mathrm{t} / \mathrm{h}$. The result shows the changes of unburned carbon produced during the simulation with coal feeder rate varies. Coal feeder rate was determined as references point due the feeder rate normal TNBJ operation was $30 \mathrm{t} / \mathrm{h}$. From the table 3 , it is known that 32.32 have lower unburned carbon compare to $30 \mathrm{t} / \mathrm{h}$ and $26 \mathrm{t} / \mathrm{h}$. The pattern shows that the unburned carbon in the fly ash decreases as the coal feeder rate increases. Feed rate is the rate of amount of coal that was feed into the boiler to support the combustion. Thus when less coal was feed in to the boiler, the efficiency of the fire reduces and the unburned carbon of the coal escapes through flue gas to outlet. The heat in flue gas also reduces due to the less heat was produced by fireball. Meanwhile for higher feed rate, more heat is produced and the carbon will be burnt and heat from flue gas assists to burn the remaining carbon that escape with fly ash [10]. Thus the factor can be concluded as input parameter that influences the production of unburned carbon. The coal feeder rate does influence the unburned carbon level in fly ash. 


\subsubsection{Excess Air (\%)}

The excess air in boiler also considered as influencing factor for unburned carbon level. Thus, the parameter was assessed by using CFD method by adjusting the percentage of excess air in the boiler. From the simulation, it was shown that the higher the percentage of excess air, the higher the unburned carbon at outlet. The result was tabulated in Table 4 below for easier understanding.

Table 4. Estimated unburned carbon in flue gas for different percentage of excess air in boiler

\begin{tabular}{|c|c|}
\hline Excess Air (\%) & Unburned Carbon (ppm) \\
\hline 5 & 0.094 \\
\hline 5.26 & 0.064 \\
\hline
\end{tabular}

The amount of unburned carbon produced at different percentage of excess air in the boiler. The $5 \%$ produces $0.094 \mathrm{ppm}$ of carbon oxide meanwhile $5.26 \%$ of excess air produces 0.064 which is less compare to $5 \%$ of excess air. From the result in table 4 , it shows that more excess air reduces amount of unburned carbon produced in fly ash. This due to the more excess air will help the coal combustion to undergo more coal burning and more excess air will eventually increase burnout of the remaining unburned carbon during combustion. This eventually will produce less unburned carbon in fly ash. Although more excess proved to reduce unburned carbon in fly ash but if the excess air more than optimum level, it will reduce boilers efficiency and lead to other technical issues such as higher level of Nitrogen Oxide (NOx) and Carbon Dioxide (CO) [11]. The percentage excess air does influence the unburned carbon level.

\subsection{Best ANN model}

After all the simulation the lowest RSME from each hidden layer was compared to obtained best model to use for intelligent monitoring system of unburned in fly ash. The RSME from each hidden layer was listed in Table 3.5 below for comparison and best model selection.

Table 5. Summarized of the best model for each hidden layer

\begin{tabular}{|c|c|c|c|}
\hline Training Algorithm & Architecture & Activation Function & RMSE \\
\hline trainlm & 9HL1 & $\mathrm{T}+\mathrm{T}$ & 0.047 \\
\hline trainscg & 5HL1-4HL2 & $\mathrm{P}+\mathrm{T}+\mathrm{T}$ & 0.148 \\
\hline
\end{tabular}

The RSME obtained for each hidden layer can be observed in Table 5 above. The lowest RSME among both hidden layer are 0.047 from 1 hidden layer. The error was so minimal compared to 2 hidden layers which were at 0.148 . Thus it is decided that the best model for this monitoring system will consists of 1 hidden layer, trained using trainlm as training function and consists of combination of tansig and tansig as its activation function[12]. Meanwhile it consists of 9 neuron in its hidden layer.

\section{Conclusion}

All the parameter was proved to influence the production of unburned carbon in fly ash. This was proved by using CFD simulation method and a basic study was done on the production 
of unburned carbon for each parameter and was discussed briefly. ANN model was developed using MATHLAB software and the model was decided to be use 1 hidden layer or 2 hidden layers. A total of the 9 input parameters were used to develop an intelligent monitoring system. From the 9 input parameters just 4 parameters was used for CFD simulation because the one parameter represent same type of input parameter. The model that was selected as the best model to be used for the intelligent monitoring system for unburned carbon in fly ash are made of 1 hidden layer with 9 neuron in it. The model uses combination of tansig and tansig as activation function and trainlm as training algorithm. The model produces RSME of 0.046637 compare to 2 hidden layer which produce RSME of 0.14797. Hence this model can be used for prediction of unburned carbon $\mathrm{n}$ fly ash. Meanwhile the training algorithm that was selected for this model are trainlm because it produced less error compare to other training algorithm using same activation function. By using this model, an intelligent monitoring system can be built and to predict the higher unburned carbon in fly ash and achieve more sustainable business and more environmentally friendly power plant.

The authors would like to express our gratitude to the power generation unit, institute of power engineering Universiti Tenaga Nasional (UNITEN) TNB Janamanjung and Ministry of Higher Education (MOHE), Malaysia for the opportunity to sponsorship this corresponding research under the FRGS research fund with the project code 20160103FRGS.

\section{References}

1. Why Use Fly Ash, [Online]. Available: http://www.proash.com / wordpress /?page_id=95. [Accessed 8 July 2015].

2. Katarzyna Styszko-Grochowick,Janusz Goles and Henryk Jankowski (2003), "Characterization of the coal fly ash for the purpose of improvement of industrial online measurement of unburned carbon", [Online]. Available: http://www.sciencedirect.com/science/article/pii/S0016236104000845 [Accessed 8 July 2015].

3. A.Schneider, R.Chabicosky and A.Aumuller (1998), "Optical sensor system for the online measurement of carbon in fly-ash", [Online]. Available: http://www.sciencedirect.com/science/article/pii/S0924424797017238. [Accessed 8 July 2015].

4. Javier Pallares, Inmaculada Arauzo, Enrique Teruel (2008), "Development of an engineering system for unburned carbon prediction", [Online]. Available: http://www.sciencedirect.com/science/article/pii/S0016236108002780. Accessed 10 November 2015].

5. Zhou Hao, Xinping Qian, Kefa Cen and Jian Fan (2003), "Optimizing pulverised coal combustion performance based on ANN and GA", [Online]. Available: http://www.sciencedirect.com/science/article/pii/S0378382003001553. [Accessed 14 September 2015].

6. S.Tronci,R.Baratti and A.Servida (2002), "Monitoring Pollutant emissions in a 4.8 MW Power Plant Through Neural Network", [Online]. Available: http://www.sciencedirect.com/science/article/pii/S0925231201006178. [Accessed 14 September 2015].

7. Jiejin Cai, Xiaoqian Ma and Qiong Li (2008), "On-line monitoring the performance of coal-fired power unit: A method based on support vector machine", [Online]. Available: http://www.sciencedirect.com/science/article/pii/S1359431108004651. Accessed 10 November 2015]. 
8. Weiping Yan and Jun Li (2009), "Modeling of the Unburned Carbon in Fly Ash", [Online]. Available: http://www.scirp.org/journal/PaperDownload.aspx?paperID=935. [Accessed 10 November 2015].

9. Jun-Li, Radoslaw Jankowski, Michal Kotecki, Weitong Yang, Dariusz Szewczyk, Artur Brdekiewicz, and Wlodzimier Blaisk (2012), "CFD Approach of Unburned Carbon Reducction on Pulverised Coal Boiler" [Online]. Available:https://pure.strath.ac.uk/portal/files/43323298/Li_etal_EAF_2012_CDF_app roach_of_unburned_carbon_reduction_on_pulverized.pdf. [Accessed 31 January 2016].

10. Jong-Min Lee, Dong-Won Kim and Jae-Sung Kim (2011), "Unburned carbon fraction with operation variables in a commercial circulating fluidized bed during co-combustion of various antarcits". [Online]. Available: http://asiatec2013.spekorea.org/PDF/KJChE/KC29/KC29-4-0452.pdf. [Accessed 31 January 2016].

11. Combustion. [Online]. Available: http://www.e- inst.com/docs/Combustion-Booklet2013.pdf. [Accessed 31 January 2015]

12. Neural Network Toolbox. [Online]. Available: http://www.mathworks.com/products/neural-network/features.html\#networkarchitectures. [Accessed 31 January 2016] 